\title{
Mission Profile-Oriented Design of Battery Systems for Electric Vehicles in MATLAB/Simulink ${ }^{\circledR}$
}

\author{
T. Debreceni ${ }^{1}$, G. Gy. Balázs ${ }^{2}$ and I. Varjasi ${ }^{1}$ \\ ${ }^{1}$ Department of Automation and Applied Informatics, Budapest University of \\ Technology and Economics, Budapest, Hungary, E-mails: tibor.debreceni@aut.bme.hu, \\ istvan.varjasi@aut.bme.hu \\ ${ }^{2}$ Siemens Zrt., Budapest, Hungary, E-mail: gergely.balazs@siemens.com
}

\begin{abstract}
Due to the nonlinear characteristics of the battery cells and the non-static power demand of the electric vehicles (EV) during their mission profiles, the dynamic behavior of the system cannot be statically calculated and analyzed in course of the electrical design of the battery system (BS). In this paper, a simulation environment is presented as a tool for mission profileoriented electrical design and performance analysis of BS in drives of e-cars and e-aircrafts. This allows effective design and rapid verification of the system level requirements. The model design is submitted through the introduction of the operation with equations and simulation results in MATLAB/Simulink ${ }^{\circledR}$. The paper describes a case study, the model performance is investigated, where the New European Driving Cycle (NEDC) is taken as basis. The BS contains a battery pack (BP) of lithiumion cells with relatively high energy- and power density.
\end{abstract}

\section{Key words}

Battery energy storage, battery model, battery simulation, battery optimization, electric vehicle.

\section{Introduction}

Since the highest gravimetric and volumetric energy density parameters of the lithium cells available on the market are still lower in order of magnitudes than in case of gasoline, the energy efficiency is the most important factor next to safety and reliability of the BS. In most EV applications, the mission profile is calculated as an important part of the technical requirement specification. From the drive system point of view, the mechanical structure of the whole vehicle with all the friction and wheel losses and external resistances can be considered as a summation load on the motor shaft (Fig. 1). From another point of view, the required shaft power can be derived from the mission profile when the latter is obtained in form of power demand curve of the vehicle against the motor to reach a related velocity. Maximum shaft load is calculated in the early design phases (in cooperation with the motor design or selection). It can also be said, that the efficiency of the inverter and the motor is well-known based on quite well-defined measurements.
Therefore, by transferring the mission profile to the DC link (Fig. 2), the optimization of the BS can be realized in a generalized simulation environment, and hereby, the energy efficiency can be increased.

\begin{tabular}{l|l}
$\begin{array}{l}\text { Battery } \\
\text { pack }\end{array}$ & $\begin{array}{c}\text { Connection } \\
\text { circuit }\end{array}-\begin{array}{l}\mathrm{DC} \\
\text { link }\end{array}-\begin{array}{l}\text { 3-phase } \\
\text { inverter }\end{array} \begin{array}{l}\text { Motor+ } \\
\text { loaded } \\
\text { shaft }\end{array}$ \\
\hline
\end{tabular}

Fig. 1. EV drive chain.

The typically used Thevenin-based battery models or static calculations for battery runtime and electrical sizing are not suitable for efficient design and energy optimization. The design software tools for BS on the market, in turn, use black boxes, thus the user cannot modify them if it is needed for a special requirement analysis or even not allowed to look inside the boxes. This has motivated the creation of an offline simulation environment for mission profile-oriented BS design in MATLAB/Simulink ${ }^{\circledR}$, which can easily be configured and fit to the given application from the cell selection to the system verification of the requirements, e.g.: energyand power demand, voltage level range over time. By this simulation-aided design, also the iteration loop between mechanical- and electrical design can be managed more efficiently.

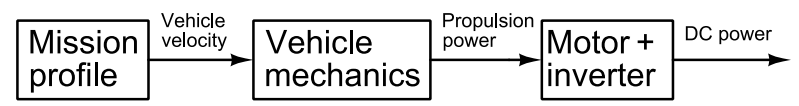

Fig. 2. Power transfer to the DC link.

The paper is organized as follows. Firstly, we shall examine modeling considerations and assumptions in section 2. In section 3, simulation environment is introduced, where model integration into Matlab/Simulink ${ }^{\circledR}$ is discussed. After a short review on the top level model, the results will be introduced in section 4 for a case study. After a review on the model performances and simulation results, the conclusion deals 
with the summation and evaluation of the designed environment in section 5 .

\section{System model design}

The block diagram of the modeled system can be seen in Fig. 1. When creating the model of the system, the aim was essentially to take into consideration only the most necessary parameters and dependencies that are needed to allow us to observe and evaluate the dynamic behavior of the BS. The basic concept for the system generalization was to take the mission profile into account at the stage of the DC link, hereby there is no need for inverter and motor modeling, which are not in the focus here.

\section{A. System parts}

Battery pack: In order to maintain an improved BP model, at first, the battery cell models and the question of the extension to pack level were investigated. The battery cell modeling has been researched for many years, which has two main driving forces in respect of mainly industrial applications. One is the offline, i.e. computer-based and continuous-time simulation purpose with floating-point number representations. The other is the online, i.e. discretized, fixed-point implementation in microcontroller of Battery Management System (BMS) in order to achieve better accuracy in State-of-Charge (SoC) estimation algorithms. In both respects, many battery cell models were examined. The electrochemical models [1]-[4] are rather used for physical design of batteries and focus on power generation aspects. Mathematical models [5], [6] are too abstract to represent any physical meaning, and cannot offer voltage-current characteristic. Using the benefits of Thevenin-based [7], [8], impedance-based [9], [10] and runtime-based [11], [12] electrical models, a combined battery cell model was proposed by Min Chen and Gabriel A. Rincón-Mora [13], which is widely used in practical applications due to its simplicity, scalability and effectiveness.

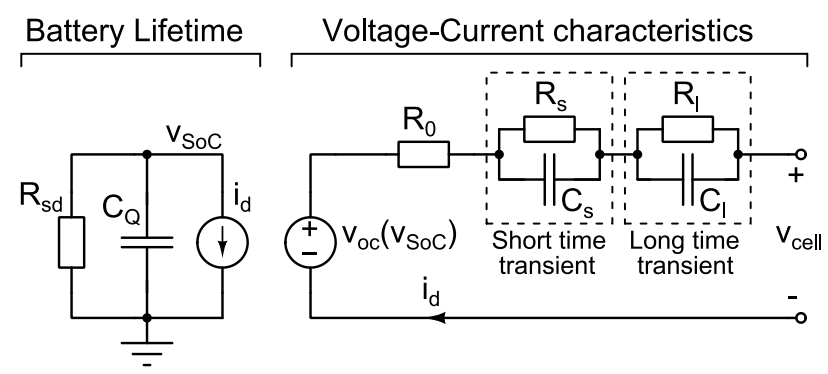

Fig. 3. Combined electrical battery cell model.

In Battery Lifetime part, $\mathrm{v}_{\mathrm{SoC}}$ is the voltage representation of the SoC (per unit) measured on $\mathrm{C}_{\mathrm{Q}}$ capacitor, which represents the cell capacity in Ampere-seconds. The resistor $R_{s d}$ is used to characterize the self-discharge energy loss when the battery is stored for a long time. These elements are inherited from runtime-based models. The RC network, similarly to the Thevenin-based models, represents the transient response. On one hand, using two $\mathrm{RC}$ time constants is the practically best trade-off between accuracy and computational complexity [13], [15]. On the other hand, when this equivalent circuit is considered as a reduced order model based on electrochemistry principles, the second-order RC network represents the effective double polarization such as electrochemicaland concentration polarization separately [14]-[16]. Being a dynamic system, all the parameters in the combined model theoretically varies with current, temperature, cycle-number and SoC [17]. However, within certain error tolerance, some parameters were simplified to be independent from the mentioned variables.

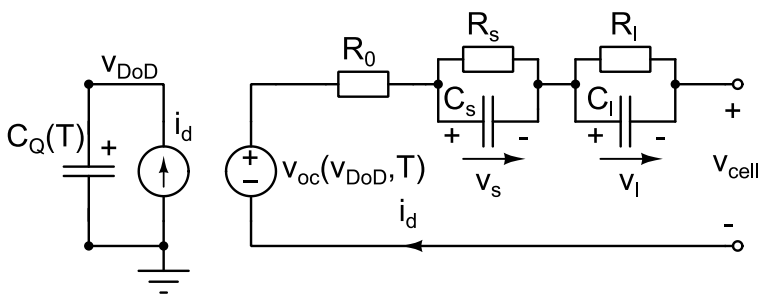

Fig. 4. Chosen electrical battery cell model.

Based on the combined model, the used model can be seen in Fig. 4, and its state equations can be followed in (1). The sign of the cell current $\left(i_{d}\right)$ is positive when the cell is discharged, and negative when charged.

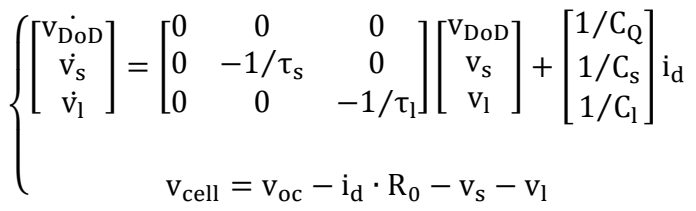

where $\tau_{\mathrm{s}}=\mathrm{R}_{\mathrm{s}} \mathrm{C}_{\mathrm{s}}$ denotes the short time-constant and $\tau_{1}=\mathrm{R}_{1} \mathrm{C}_{1}$ is the long time-constant, and $\mathrm{v}_{\mathrm{DoD}}=1-\mathrm{v}_{\mathrm{SoC}}$ means the Depth-of-Discharge (DoD).

The self-discharge effect is ignored due to the very low per month self-discharge rate of advanced lithium-ion cells, and because frequent usage of the batteries is assumed. The dependencies were obtained as continuous functions derived from the curves in datasheets. The temperature-dependency of the usable (or discharge) capacity is taken into consideration in the model based on the characteristic shown in Fig. 5, which is implemented in the case study.

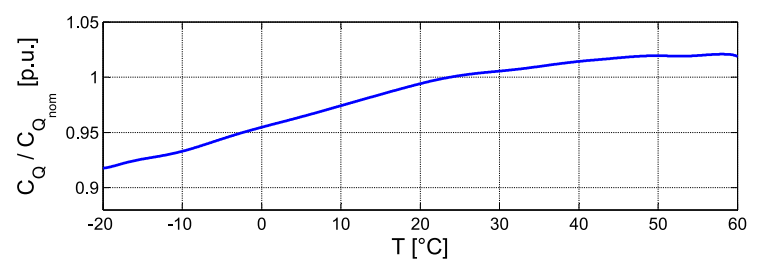

Fig. 5. Fitted curve for $\mathrm{C}_{\mathrm{Q}}(\mathrm{T})$ per units.

Besides the temperature, the cell current also affects the usable capacity, which is known as Peukert-effect. Although, in the datasheet, the current axis of the discharge capacity curve involves only 4 measurement point in a tight range of $[0.4 ; 11] \mathrm{A}$, it shows a significant deviation from what Peukert-law would predict. The current-dependency is not considered in the model. After about 300 cycles, the battery cell usable capacity is 
decreased to $80 \%$ of the nominal value, and the reduction is approximately proportional to the cycle number. Even though, the model does not contain this dependency because this effect is not analyzed during one mission profile. It is only taken into account by a parameter setting of decreased cell capacity before simulation started.

The discharge curves are served in the datasheet as functions of discharge capacity and measured at 6 temperature values. The DoD axis was practically scaled to the range of 0 to 1 , thus this is taken as basis of DoD. After offsetting these discharge curves to compensate the initial voltage drop on the ohmic internal resistance, a 2D look-up table was implemented, which is plotted in Fig. 6.

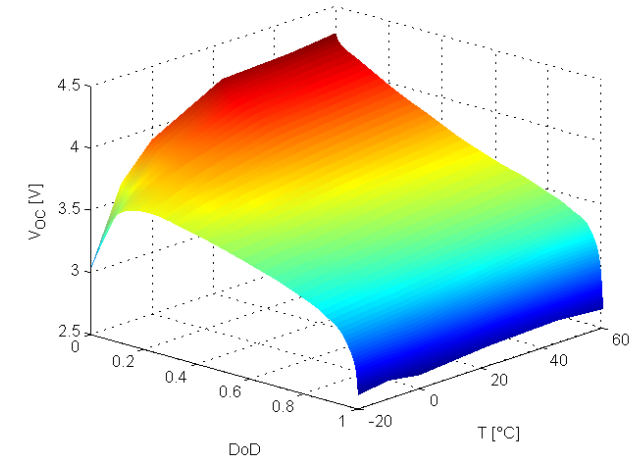

Fig. 6. $\mathrm{v}_{\mathrm{oc}}(\mathrm{DoD}, \mathrm{T})$ function realized by $2 \mathrm{D}$ lookup table.

Hereby, at first round, there was no need for identification of the model parameters. Thus, although the RC network elements are constants, the battery cell model can still simultaneously predict runtime, steady-state, and transient response capturing all the dynamic electrical characteristics of the cell, such as usable capacity, opencircuit voltage, and transient response.

In this study, the differences of capacity, current, temperature, SoC and State-of-Health $(\mathrm{SoH})$ are taken into account neither between parallel cells nor between serial cells. Hereby, the circuit of the BP model can be the same as used in the cell model, and the parameters/quantities are modified by scaling factors shown in Table I.

Table I. - Scaling factors for BP model.

\begin{tabular}{|c|c|c|c|c|c|c|c|}
\hline Param. & $\mathrm{C}_{\mathrm{Q}}$ & $\mathrm{v}_{\mathrm{oc}}$ & $\mathrm{R}_{0}$ & $\mathrm{R}_{\mathrm{s}}$ & $\mathrm{C}_{\mathrm{s}}$ & $\mathrm{R}_{\mathrm{l}}$ & $\mathrm{C}_{\mathrm{l}}$ \\
\hline Factor & $\mathrm{N}_{\text {row }}$ & $\mathrm{N}_{\text {series }}$ & $\mathrm{k}$ & $\mathrm{k}$ & $\mathrm{k}^{-1}$ & $\mathrm{k}$ & $\mathrm{k}^{-1}$ \\
\hline
\end{tabular}

where $\mathrm{k}=\mathrm{N}_{\text {series }} / \mathrm{N}_{\text {row }}$.

Basic building element of the pack is called row, which contains $\mathrm{N}_{\text {row }}$ number of cells connected in parallel. The $\mathrm{BP}$ is built-up by $\mathrm{N}_{\text {series }}$ number of rows connected in series. After the extension of the used cell model by scaling factors, the block diagram of the BP model can be seen in Fig. 7. Now, $v_{\text {pack }}$ stands for the pack output voltage that includes two components. One is the opencircuit voltage, which is read from the $2 \mathrm{D}$ lookup table using DoD and temperature by linear interpolation. The other is the dynamic effect of the internal impedance. With such combination, the individual shortcomings can be overcome [15].

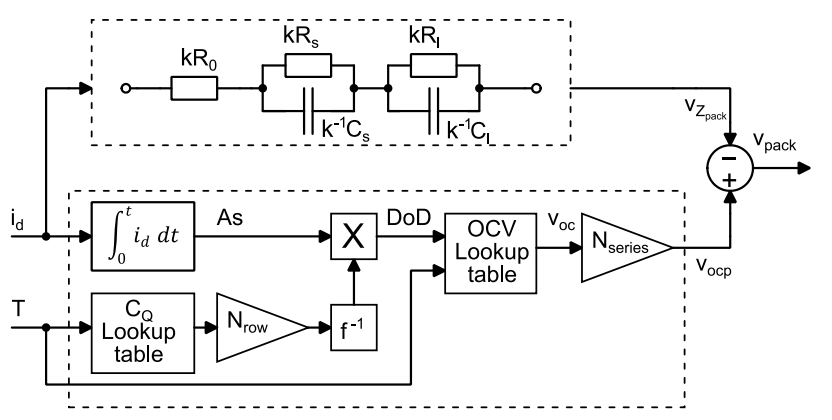

Fig. 7. Block diagram of the battery pack model.

Connection circuit and cabling: Pre-charge of the DC link capacitor and disconnection possibility of the BP from the load is ensured by the connection circuit in EV systems.

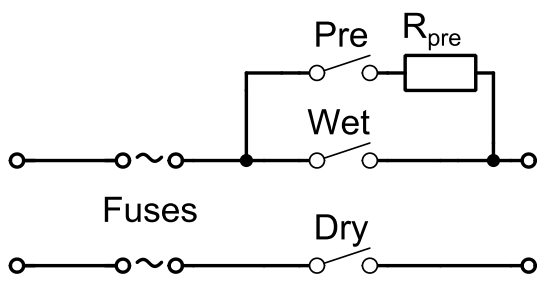

Fig. 8. Connection circuit setup.

In EV applications, the used DC contactors are rated for typically $100-1500 \mathrm{~V}_{\mathrm{DC}}$ operating voltage and 500-2000 $\mathrm{A}_{\mathrm{DC}}$ breaking capacity. The on-delay and the related make arcing effect are not so important than the off-delay and the related break arcing phenomenon, which can cause serious damage in case of short circuit failure. Since this study is not dealing with the verification of either the connection circuit, pre-charge or the protection mechanisms, only the normal operating mode equivalents are considered. In normal operating mode, the DC contactors, fuses and all the high power contacts in the drive system have resistance. The resistances of the fuse and the DC contactor are typically given at the rated currents. In this model these are constants, in order $\mathrm{R}_{\text {fuse }}$ $=0.7 \mathrm{~m} \Omega$ and $R_{\mathrm{dcc}}=0.2 \mathrm{~m} \Omega$. In EV systems, the high power cabling is relatively not long and relatively wide cross sections $\left(>25 \mathrm{~mm}^{2}\right)$ are used, but the resistance and the inductance of the total cabling counts. Now, the cabling parameters are $\mathrm{R}_{\mathrm{c}}{ }^{\prime}=0.7 \Omega / \mathrm{km}$ and $\mathrm{L}_{\mathrm{c}}{ }^{\prime}=1 \mu \mathrm{H} / \mathrm{m} . \mathrm{R}_{\mathrm{r}}$ is the resulting resistance, which is calculated as in (2).

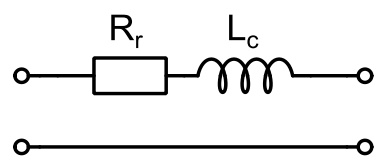

Fig. 9. Connection circuit and cabling model.

In the case study, a usual 2 meters of DC cables are taken, so the parameters are $\mathrm{R}_{\mathrm{c}}=1.4 \mathrm{~m} \Omega$ and $\mathrm{L}_{\mathrm{c}}=2 \mu \mathrm{H}$.

$$
\mathrm{R}_{\mathrm{r}}=2 \cdot \mathrm{R}_{\text {fuse }}+2 \cdot \mathrm{R}_{\mathrm{dcc}}+\mathrm{R}_{\mathrm{c}}
$$


Load profile: The vehicle mission profile is given in velocity curve as a function of time. In this paper, a static vehicle model is used, so the load torque is assumed to be equal to the torque generated by the drive system. Therefore, the power demand of the vehicle against the motor $\left(\mathrm{p}_{\text {mprofile }}\right)$ is assumed to be proportional to the vehicle velocity $\left(\mathrm{v}_{\text {vehicle }}\right)$. Detailed dynamic vehicle model design is not the scope of this paper, but can be a part of further developments. The shaft load is assumed to be proportional to this power demand, and calculated as in (3).

$$
\begin{gathered}
\mathrm{p}_{\text {mprofile }}(\mathrm{t})=\frac{\mathrm{v}_{\text {vehicle }}(\mathrm{t})}{\mathrm{v}_{\text {vehicle }_{\text {max }}}(\mathrm{t})} \cdot \mathrm{P}_{\text {motor }_{\text {nom }}} \\
\mathrm{p}_{\text {shaft }}(\mathrm{t})=\frac{\mathrm{p}_{\text {mprofile }}(\mathrm{t})}{\eta_{\mathrm{vs}}}
\end{gathered}
$$

where $\mathrm{P}_{\text {motornom }}$ denotes the motor nominal power rating, $\eta_{\mathrm{vs}}$ represents an efficiency of the coupling between the vehicle power demand against motor and the shaft power, which is strongly related to the mechanical structure, frictional and wheel losses and external resistances. Considering the inverter and motor efficiencies and the losses of AC cabling, the power demand on the DC link is determined as it is described in (4).

$$
\mathrm{p}_{\text {DClink }}(\mathrm{t})=\frac{\mathrm{p}_{\text {shaft }}(\mathrm{t})}{\eta_{\text {inv }} \cdot \eta_{\text {motor }}}+\mathrm{p}_{\text {loss }_{\mathrm{AC}}}
$$

where $\eta_{\text {inv }}$ denotes the inverter efficiency, $\eta_{\text {motor }}$ stands for the motor efficiency and $\mathrm{p}_{\text {lossAC }}$ is the power loss caused mainly by the impedance of the AC cabling between inverter and motor. The last one can be zero without any significant error if the inverter and motor are assumed to be assembled very close to each other and connected via very short cabling with wide cross-sections that has not considerable impedance in the frequency range of most EV drives. DC link capacitor is loaded by a current generator whose current $\left(\mathrm{i}_{\text {drive }}\right)$ is calculated by a continuous-time PI power controller as follows:

$$
\begin{aligned}
& i_{\text {drive }}(t)=K_{P} \cdot e_{p}(t)+K_{I} \int_{0}^{t} e_{p}(t) d t \\
& e_{p}(t)=p_{D C l i n k}(t)-v_{D C}(t) \cdot i_{\text {load }}(t)
\end{aligned}
$$

Hereby, the inverter and motor modeling issues can be avoided and the simulation environment becomes more generalized without decreasing the optimization possibilities of the BS.

\section{B. System model}

The equivalent circuit model of the BS with the load can be seen in Fig. 10. According to this equivalent circuit model, the system behavior can be followed based on the system state equations in (6) and (7).

$$
v_{D C}=\frac{1}{C_{D C}} \int_{0}^{t}\left(i_{\text {load }}-i_{\text {drive }}\right) d t+v_{D C}(0)
$$

where $C_{D C}=560 \mu \mathrm{F}, \mathrm{v}_{\mathrm{DC}}(0)$ is the initial voltage of DC link that is set to $\mathrm{v}_{\text {pack }}(0)$, which means that the DC capacitor is considered to be pre-charged.

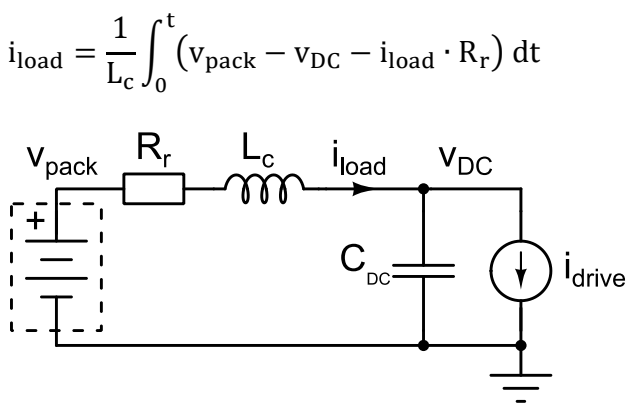

Fig. 10. Equivalent circuit model of the system.

\section{Simulation environment}

The top-level environment can be seen in Fig. 11.

The Connection circuit + cabling and the DC link blocks have been implemented directly from the equations (6) and (7), and it is also true in case of the Power Controller block for equation (5).

The Battery Pack block is designed using the state equations in (1) and the block diagram in Fig. 7. The summation SoC for the BP can be estimated almost independently. Since quite an accurate balancing is assumed to be implemented in the BS, the resulting SoC for the BP can be estimated as in (8).

$\operatorname{SoC}_{\%}(t)=\operatorname{SoC}_{\%}(0)-\frac{100 \%}{3600 \cdot N_{\text {row }} \cdot C_{Q}(T)} \int_{0}^{t} i_{\text {load }}(t) d t$

where $\mathrm{C}_{\mathrm{Q}}(\mathrm{T})$ is determined in Ampere-hours, and $\mathrm{SoC}_{\%}(0)$ is the initial SoC value of BP that is set to $100 \%$ in the simulations presented in this paper.

The Mission profile block is realized using Signal Builder $^{\circledR}$, in which the profile of NEDC [18] is built-up in order to verify the designed environment in a case study. Certainly, any kind of velocity curve can be edited for a given application, or even directly the power demand curve can be inserted when available. The builtup NEDC profile is shown in Fig. 12.

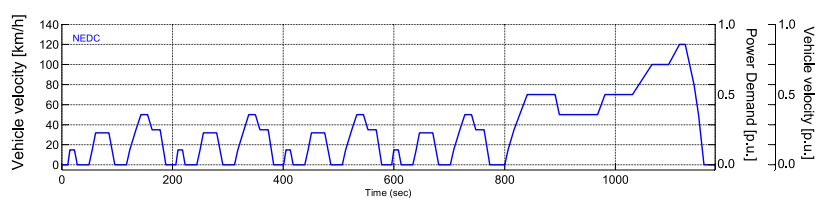

Fig. 12. NEDC profile implemented in Signal Builder ${ }^{\circledR}$.

In order to supervise the cell-level currents relatively to their maximum continuous discharge current rate $\left(\mathrm{I}_{\mathrm{MCD}}\right)$, a multiplying factor $\left(\mathrm{M}_{\mathrm{f}}\right)$ is obtained for the load current, and calculated as in (9), which is used in the next section.

$$
\mathrm{M}_{\mathrm{f}}=\left(\mathrm{N}_{\text {row }} \cdot \mathrm{I}_{\mathrm{MCD}}\right)^{-1}
$$



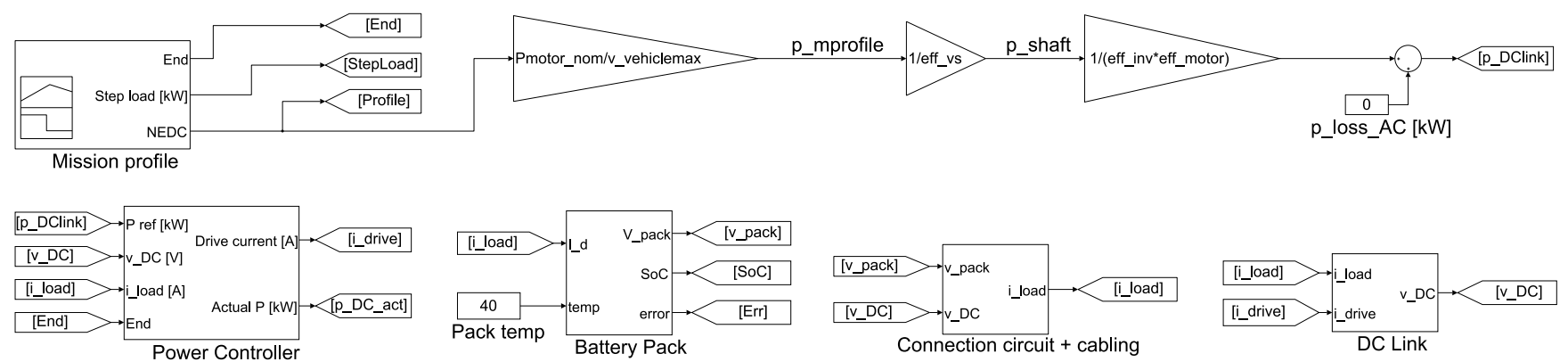

Fig. 11. Top level simulation environment in MATLAB/Simulink ${ }^{\circledR}$.

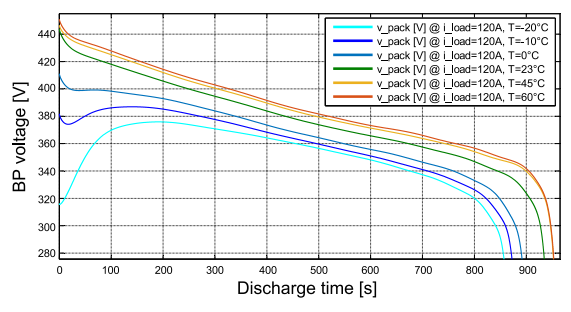

(a)

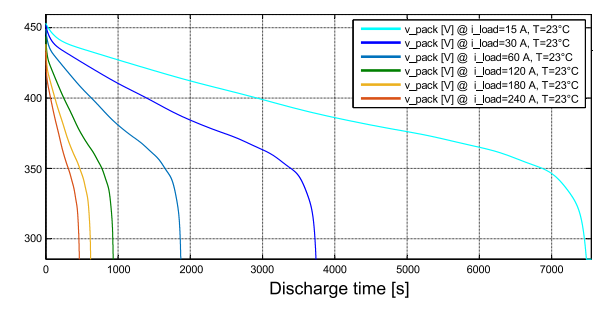

(b)

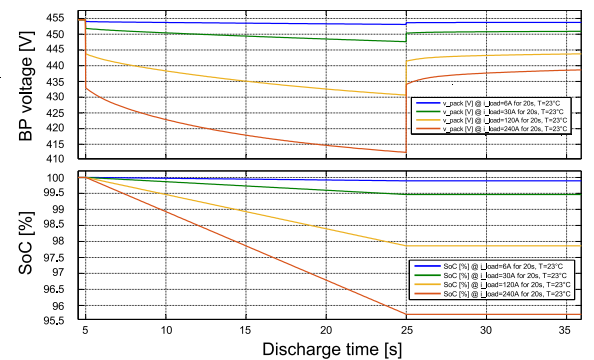

(c)

Fig. 13. Battery pack model continuous discharge performances for (a) temperature, (b) current. Pulse (20 sec) discharge performances (c) for current.

\section{Results}

The results and verification of the designed simulation environment is introduced through a case study.

Suppose that the NEDC is the required mission profile, in addition, the vehicle-, motor- and inverter-specific parameters are shown in Table II. For the case study, a cylindrical lithium-ion cell was selected, which has a normal operating voltage range of $2.5-4.2 \mathrm{~V}_{\mathrm{DC}}$ with nominal voltage of $3.6 \mathrm{~V}_{\mathrm{DC}}$. The $\mathrm{I}_{\mathrm{MCD}}$ is $20 \mathrm{~A}$, which is quite high in respect of that it is rather an "energy-cell" of cylindrical cells. The density parameters are listed in Table II.

Table II. - Case study parameters.

\begin{tabular}{|l|l|}
\hline Inverter nominal voltage $\left[\mathrm{V}_{\mathrm{DC}}\right]$ & 380 \\
\hline Inverter minimum voltage $\left[\mathrm{V}_{\mathrm{DC}}\right]$ & 180 \\
\hline Inverter maximum voltage [ $\left.\mathrm{V}_{\mathrm{DC}}\right]$ & 460 \\
\hline Inverter efficiency at nominal power [ ] & 0.98 \\
\hline Vehicle maximum velocity [km/h] & 140 \\
\hline Motor nominal power [kW] & 85 \\
\hline Motor efficiency at nominal power [ ] & 0.9 \\
\hline Vehicle to shaft mechanical coupling [ ] & 0.7 \\
\hline Battery cell nominal capacity [Ah] & 2.6 \\
\hline
\end{tabular}

Based on the voltage range required by the inverter, $\mathrm{N}_{\text {series }}$ can be easily determined as 108 . For a quick tryout, the $\mathrm{N}_{\text {row }}$ has been estimated to 12 , based on the followings. The mission profile has about $85 \%$ maximum point of power demand, and based on the efficiencies listed in the Table II., the needed BP power can be estimated as about $100 \mathrm{~kW}$.

At first, the voltage-current characteristics and the dynamic performance of the battery pack has been analyzed setting continuous- and pulse discharge conditions due to verification aspects. Some of the results can be seen in Fig. 13.

In case of continuous discharge, the scaled $\mathrm{v}_{\mathrm{oc}}$ characteristics are observed and the runtime is examined on Fig. 13. (b). The proper temperature dependency can be seen on Fig. 13. (a), that is, the lower the pack temperature is, lower the power and energy are available at the terminals. In case of a $20 \mathrm{sec}$ pulse discharge, the exponential discharge curve can be followed after the voltage drop on the internal impedance. After the pulse discharge, the so called relaxation phenomenon can be followed in Fig. 13. (c).

The first simulation for the mission profile showed, that the estimation of $\mathrm{N}_{\text {row }}=12$ was acceptable in respect of $\mathrm{SoC}$, but during the end (extra-urban) cycle of NEDC, the cell-level current reached the maximum discharge current rate, as shown in Fig. 14.

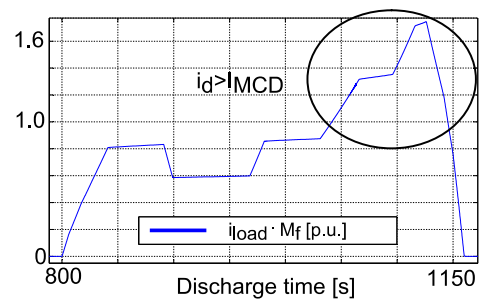

Fig. 14. Cell-level over-current error during NEDC.

This error can be avoided quickly by increasing $\mathrm{N}_{\text {row }}$ in the parameter set. This problem would not have turned out yet, if we would rely on the static BP sizing calculations. The resulted simulation of the BS in case of NEDC can be seen in Fig. 15. 


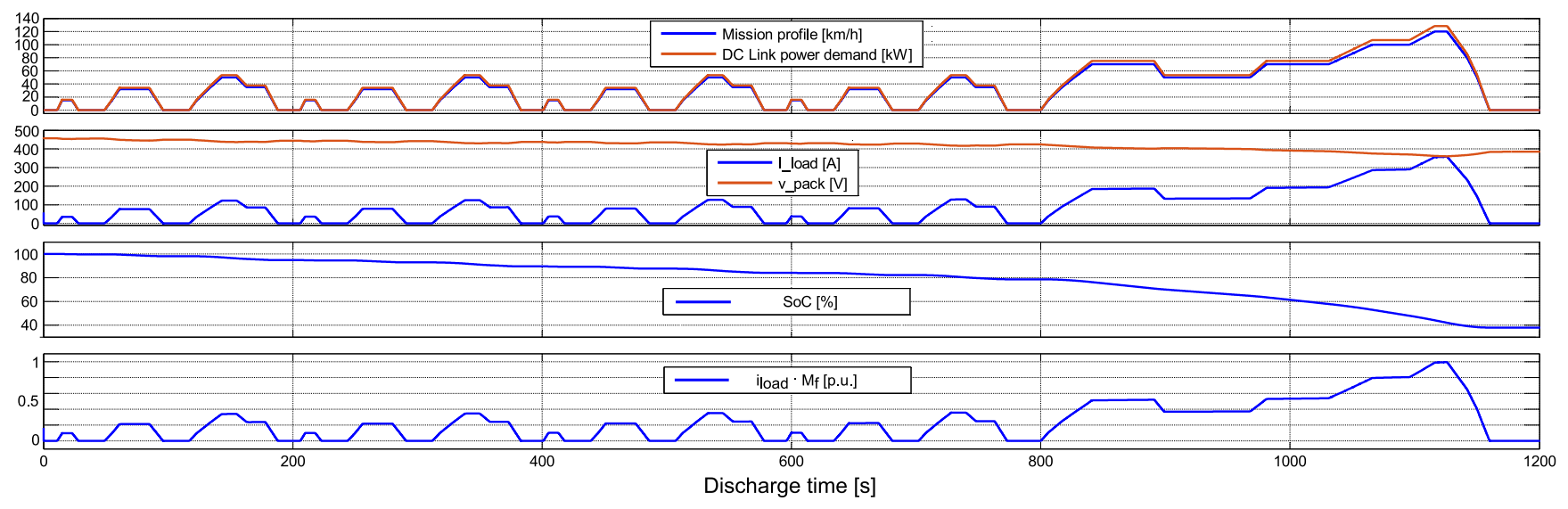

Fig. 15. BS simulation for NEDC mission profile.

\section{Conclusion}

The aim of the present paper was to give an overview of the modeling approach of a BS in order to create a simulation environment with electrical design aiding and optimization purposes for EVs. The discussion has clearly showed the considerations taken to get a generalized and easy-to-set MATLAB/Simulink ${ }^{\circledR}$ implementation. This allows an effective design and rapid verification of the system level requirements, and allows the designer to observe the dynamic behavior of the system. The model performance is investigated and the sufficient DC, runtime and transient behavior of the BP is examined. In conclusion, we can say that the presented simulation environment can be used for optimizing the BS for optional mission profiles.

\section{Acknowledgement}

The authors wish to thank Dr. Frank Anton for ensuring research directions of battery systems. Thanks are also to Dr. Wolfgang Weydanz and Dr. Holger Wolfschmidt for the support in the topic of battery technologies.

\section{References}

[1] L. Song and J. W. Evans, "Electrochemical-thermal model of lithium polymer batteries," J. Electrochemical Society, vol. 147, pp. 2086-2095, 2000.

[2] P. M. Gomadam, J. W. Weidner, R. A. Dougal, and R. E. White, "Mathematical modeling of lithium-ion and nickel battery systems," J. Power Sources, vol. 110, no. 2, pp. 267-24, Aug. 2002.

[3] D. W. Dennis, V. S. Battaglia, and A. Belanger, "Electrochemical modeling of lithium polymer batteries," J. Power Source, vol 110, no. 2, pp. 310-320, Aug. 2002.

[4] J. Newman, K. E. Thomas, H. Hafezi, and D. R. Wheeler, "Modeling of lithium-ion batteries," J. Power Sources, vol. 119-121, pp. 838-843, Jun. 2003.

[5] D. Rakhmatov, S. Vrudhula, and D. A. Wallach, "A model for battery lifetime analysis for organizing applications on a pocket computer," IEEE Trans. VLSI Systems, vol. 11, no. 6, pp. 1019-1030, Dec. 2003.

[6] P. Rong and M. Pedram, "An analytical model for predicting the remaining battery capacity of lithium-ion batteries," in Proc. Design, Automation, and Test in Europe
Conf. and Exhibition, 2003, pp. 1148-1149.

[7] B. Schweighofer, K. M. Raab, and G. Brasseur, "Modeling of high power automotive batteries by the use of an automated test system," IEEE Trans. Instrumentation and Measurement, vol. 52, no. 4, pp. 1087-1091, Aug. 2003.

[8] L. Gao, S.Liu, and R. A. Dougal, "Dynamic lithium-ion battery model for system simulation," IEEE Trans. Components and Packaging Technologies, vol. 25, no. 3, pp. 495-505, Sept. 2002.

[9] S. Buller, M. Thele, R. W. De Doncker, and E. Karden, "Impedance-based simulation models of supercapacitors and Li-ion batteries for power electronic applications," in Conf. Rec. 2003 Industry Applications Conf., vol. 3, pp. 159601600.

[10] P. Baudry, M. Neri, M. Gueguen, and G. Lonchampt, "Electro-thermal modeling of polymer lithium batteries for starting period and pulse power," J. Power Sources, vol. 54, no. 2, pp. 393-396, Apr. 1995.

[11] S. C. Hageman, "Simple pspice models let you simulate common battery types," EDN, pp. 17-132, Oct. 1993.

[12] S. Gold, "A pspice macromodel for lithium-ion batteries," in Proc. 12th Annual Battery Conf. on Applications and Advances, 1997, pp. 215-222.

[13] Chen, M., Rincón-Mora, G.A: “Accurate Electrical Battery Model Capable of Predicting Runtime and I-V performance", IEEE Transactions on energy conversion, Vol. 21 No. 2, 2006, p.504-511.

[14] He, H.; Xiong, R.; Fan, J., "Evaluation of lithium-ion battery equivalent circuit models for state of charge estimation by an experimental approach", Energies 2011, 4, 582-598.

[15] Shifei Yuan, Hongjie Wu and Chengliang Yin, "State of Charge Estimation Using the Extended Kalman Filter for Battery Management Systems Based on the ARX Battery Model”, Energies 2013, 6, 444-470.

[16] Rui Xiong, Xianzhi Gong, Chunting Chris Mi, Fengchun Sun: "A robust state-of-charge estimator for multiple types of lithium-ion batteries using adaptive extended Kalman filter", Journal of Power Sources, vol. 243, 2013, 805-816.

[17] Long Lam: "A Practical Circuit-based Model for State of Health Estimation of Li-ion Battery Cells in Electric Vehicles", Master of Science Thesis, University of Technology Delft, 2011.

[18] E/ECE/324, E/ECE/TRANS/505, Rev.2/Add.100/Rev.3, Regulation No. 101, 2013. 50-58. 